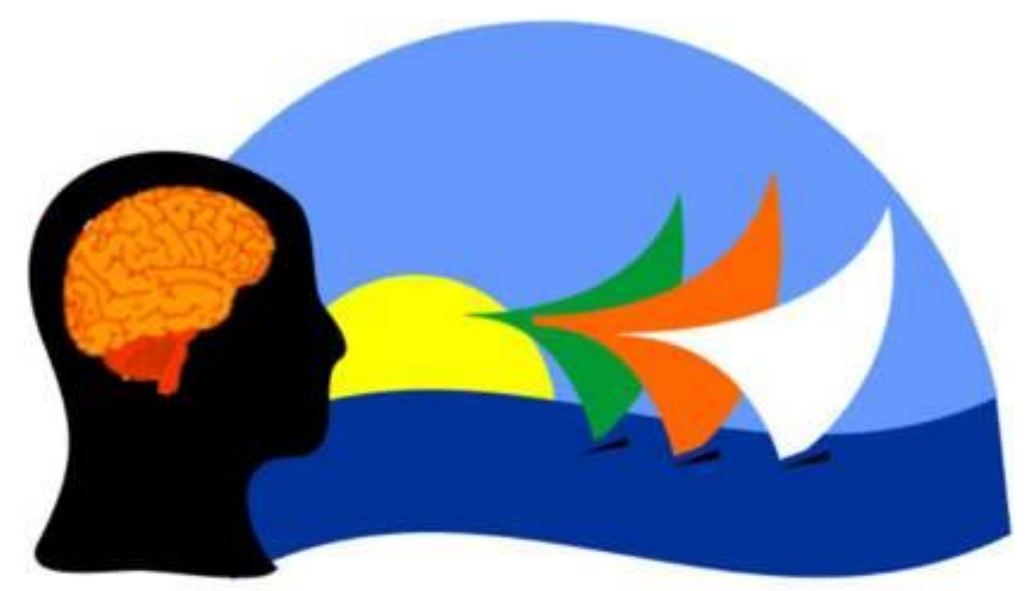

\title{
I INTERNATIONAL SYMPOSIUM IN NEUROSCIENCE
}

December, 04 - 06, 2013

Pici Campus - Universidade Federal do Ceará

Fortaleza - Ceará - Brazil

\section{ABSTRACTS}

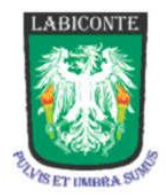




\section{ORGANIZERS}

Universidade Federal do Ceará- UFC

Instituto de Biomedicina do Semiárido Brasileiro - IBISAB

Lab. da Biologia da Cicatrização, Ontogenia e Nutrição de Tecidos - LABICONTE

\section{EXECUTIVE COMMITTEE COORDINATOR}

Dr. Reinaldo Barreto Oriá, PhD

\section{EXECUTIVE COMMITTEE}

Dr. Geanne Matos de Andrade, PhD

Dr. Veralice Meireles Sales de Bruin, MD, PhD

\section{SCIENTIFIC COMMITTEE}

Dr. Reinaldo Barreto Oriá, PhD

Dr. Geanne Matos de Andrade, PhD

Dr. Veralice Meireles Sales de Bruin, MD, PhD

INTERNATIONAL GUEST SPEAKERS

NATIONAL GUEST SPEAKERS

Dr. João Malva (Portugal)

Dr. Kenneth Norwood (USA)

Dra. Ludmila Belayev (USA)

Dr. Rodrigo Cunha (Portugal)

Dr. Romulo Antonio Fuentes (Chile)

Dra. Carolina Ramoa (USA)
Dr. Romulo Antonio Fuentes Flores

Dr. Roberto Lent

Dr. John Fontenele

Dra. Lia Bittencourt

Dr. Natanael Santos

Dr. Bradley Miller

Dr. Reinaldo Barreto Oriá

Dra. Lúcia Willadino Braga

Dr. José Arnaldo Mota Arruda

Dra. Geanne Andrade 


\section{ADDRESS}

Seara da Ciência

Campus do Pici - Universidade Federal do Ceará

Av. Humberto Monte, $\mathrm{S} / \mathrm{N}$

Fortaleza - CE - Brasil

\section{DATE/SCHEDULE}

December, 4th, $2013-07 \mathrm{~h} 30 \mathrm{~min}-18 \mathrm{~h} 00 \mathrm{~min}$

December, 5th, 2013-08h00min - 18h00min

December, 6th, $2013-08 \mathrm{~h} 00 \mathrm{~min}-12 \mathrm{~h} 00 \mathrm{~min}$

\section{SUPPORT}
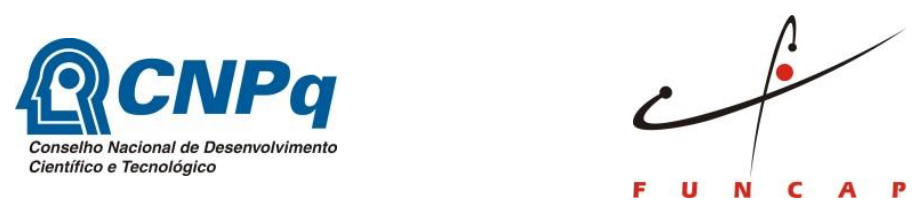

Blucher

\section{SPONSORSHIP}
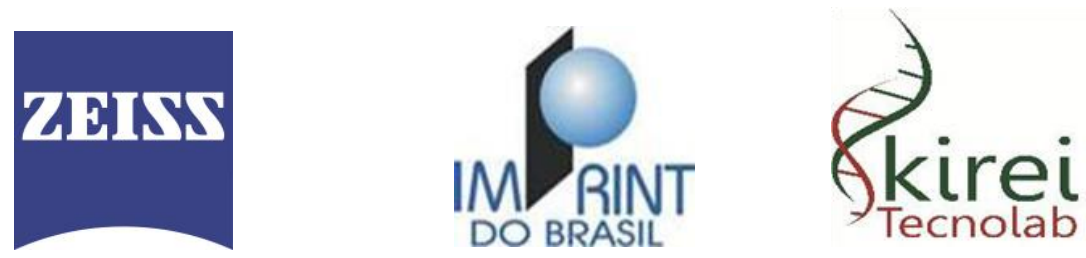

Unimed|st Fortaleza

INTERNATIONAL

STANDARD

SERIAL

NUMBER 